\title{
REGIMES ALIMENTARES E QUESTÕES AGRÁRIAS
}

Etho Roberio Medeiros Nascimento ${ }^{1}$

\section{SOBRE A OBRA}

O presente livro aborda de forma clara e expositiva o desenvolvimento do capitalismo sobre a agricultura, tendo a produção de alimentos, os regimes agroalimentares globais e a questão agrária como eixos centrais de análise. Assim, o debate sobre a industrialização e modernização da agricultura são abordados através da forma como o modo de produção capitalista se estrutura, e como este se apropria da produção de alimentos para instauração do monopólio e controle político sobre a população. Além disso, questiona-se a forma como o capitalismo tem atuado sobre a agricultura e tem afetado as questões ambientais e sociais em diversas regiões do planeta.

$\mathrm{O}$ autor traz também o debate dos regimes alimentares em uma perspectiva analítica, abordando as formas com que os sistemas alimentares interligam e transformam as diversas culturas, por meio do processo de mercantilização da agricultura. Tal conceito de regime é utilizado para definir a ordem capitalista que estrutura a produção e o consumo de alimentos, e o modo como esse modelo garantiu o processo de acumulação de bens e insumos industrializados.

Essa obra está estruturada em sete capítulos que abordam as temáticas dos regimes alimentares e a relação com as questões agrárias. Nos três capítulos iniciais, o autor aborda os regimes alimentares e seu período de duração em uma contextualização histórica, pautada pela correlação com a atual crise do sistema corporativo de produção de alimentos. Este tem provocado o distanciamento das populações entre a segurança alimentar e os níveis sociais e ambientais desejáveis. Esses capítulos iniciais debatem sobre os projetos de regimes alimentares que frequentemente associam as relações internacionais de produção e consumo de alimentos às formas de acumulação, não se referindo apenas ao alimento, mas também à política por trás das relações alimentares. $\mathrm{O}$ autor destaca ainda que $\mathrm{o}$ surgimento desses regimes se dá através de um processo de colapso ou ruptura, iniciada pela transição para uma nova dinâmica econômica global. Tal transição modifica as regras e consequências da mercantilização agrícola, e inicia um novo ciclo de expansão de diferentes divisas agrícolas.

Desse modo, o capítulo um descreve o primeiro regime agroalimentar (1870-1930), iniciado na Grã-Bretanha. A principal característica desse regime era sua dinâmica de exploração de produtos tropicais, oriundos das colônias britânicas, tendo como principais produtos os grãos e alimentos ligados à pecuária. Observa-se um processo de terceirização da produção de commodities a partir do modelo de exportação das colônias localizadas no Novo Mundo. Além da exploração da terra, a mão

\footnotetext{
${ }^{1}$ Doutorando no Programa de Pós-graduação em Desenvolvimento Rural da Universidade Federal do Rio Grande do Sul. E-mail: ethoroberio@gmail.com
} 
de obra utilizada nesses países foi fundamental para a consolidação do modelo de acumulação e rentabilidade de capital, utilizadas pelos britânicos.

Observou-se, nesse período, um salto na produção e universalização da comercialização de produtos que antes eram tidos como artigo de luxo ou especiarias de alto valor (cana-de-açúcar). Os moldes desse regime alimentar foram importantes para subsidiar também o modelo fabril emergente da era industrial que se aproximava. Entretanto, como consequência da exaustão das fronteiras agrícolas vigentes e do período de instabilidade sociopolítico vivenciado a partir do período entre guerras, este regime alimentar entrou em colapso. O fim desse regime é marcado por um período de transição, no qual houve avanço do modelo de acumulação de bens de produção e capital, e avanço da agroindustrialização americana, caracterizada por uma agricultura pautada pelas exportações nos cinturões agrícolas.

O segundo regime alimentar se deu nos Estados Unidos da América (EUA) (1950-1970) e se consolidou no período pós-guerra, marcado pela alta demanda de produtos de alimentares em países arrasados pelo conflito e em nações emergentes. Esse regime conciliava programas nacionais de agricultura intensiva em capital, baseada na especialização em commodities, e no direcionamento dos fluxos de excedentes alimentícios subsidiados pelos EUA para a Europa e ex-colônias do sul global. Com essas ações, o governo americano pode manter o preço, a competitividade e proteção mercantil de seus agricultores dentro do mercado internacional. Nesse período, construiu-se uma narrativa substancial sobre o combate à fome e à pobreza, a partir das campanhas da Organização das Nações Unidas (ONU) junto aos países subdesenvolvidos, que tiveram papel fundamental na difusão e consolidação dessas intervenções, por meio de ajudas humanitárias e políticas públicas locais.

Além disso, sustentados por discursos contra o colonialismo e o comunismo, os Estados Unidos apropriaram-se e se beneficiaram das crises humanitárias internacionais para fortalecer seus objetivos políticos e imperialistas. Os novos Estados independentes e emergentes passaram por um processo de internalização do modelo norte-americano de agroindustrialização, adotando as principais tecnologias desenvolvidas na Revolução Verde (sementes, insumos agrícolas, dentre outros). Estes ainda intensificaram suas ações para frear e arrefecer as inquietações camponesas por reforma agrária, que se deu através da mercantilização da agricultura e da intensificação das relações de mercado no campo.

Contudo, com a abertura do bloco soviético aos grãos americanos, em 1972, surgiu uma nova crise inflacionária dos alimentos, que resultou em uma tensão nos processos de acumulação; fomentando uma série de debates sobre o aumento da fome e modelos desiguais de desenvolvimento econômico. Essa crise alimentar abriu espaço para inquietações e surgimento de questões relacionadas à eficiência das políticas de ajuda alimentar e humanitária, desenvolvidas pelas 
instituições internacionais, e suas relações preferenciais no mercado de alimentos; oportunizando novas discussões sobre segurança e soberania alimentar em países subdesenvolvidos.

Já o terceiro regime alimentar, também denominado pelo autor como regime alimentar corporativo, tem início a partir de década de 1980, e vem aprofundando os efeitos do segundo regime, sendo caracterizado como um sistema cada vez mais transnacional e corporativo. Esse regime reflete bem o projeto de globalização neoliberal da política de capital, projetando uma hegemonia corporativa sustentada por finanças internacionais e regras multilaterais. O regime alimentar corporativo se dá por meio da atuação das grandes redes corporativas internacionais e pela difusão de cultivos cada vez mais especializados, balizados pela utilização de espécies transgênicas, produção de alimentos a baixo custo e intensificação da divisão internacional do trabalho. Este regime é coordenado por cadeias corporativas, cujas relações comerciais são regidas por instituições como o Fundo Monetário Internacional (FMI) e protocolados pela Organização Mundial do Comércio (OMC).

Observa-se ainda, nesse regime, o aperfeiçoamento da estrutura organizacional do setor produtivo, liderado pelas grandes empresas transnacionais do agronegócio e do varejo de alimentos. Este fenômeno se consolidou a partir da obtenção de proteções de propriedade intelectual e do modelo de agronegócio subsidiado e centralizado. Logo, o padrão agroexportador deste regime fomentou a consolidação de uma agricultura que demanda a padronização da qualidade dos produtos no mercado internacional, incorporando elementos de produção semelhante a um processo de linha de produção industrial (fordismo).

Nesse contexto, os agricultores familiares e camponeses, em geral menos capitalizados, encontram-se incapazes de atender a certas demandas ou competir em mercados com fluxos de grãos a preços tão baixos, além de serem marginalizados por políticas agrícolas que favorecem o modelo de regime corporativo e o agronegócio. Além disso, o dumping praticado pelos países desenvolvidos tem se intensificado a partir das regras de liberalização da OMC, desapossando agricultores categorizados como "ineficientes ou improdutivos" e destruindo aqueles incapazes de competir com o poder de mercado subsidiado ou monopolizado. Assim, tal cenário expõe o aprofundamento dos efeitos herdados pela Revolução Verde, com destaque para o aumento da pobreza no meio rural, fome e desigualdade social.

O quarto capítulo, fechamento da primeira metade desta obra, tem por objetivo qualificar a questão agrária em aderência ao tema dos regimes alimentares, situando as questões das transformações de classe no campo e de capitalização da terra em um contexto histórico-mundial. O autor apresenta o conceito de "questão agrária do alimento" e faz uma reflexão sobre a luta do movimento de soberania alimentar ao desnaturalizar a segurança alimentar baseada nas normas da 
indústria de alimentos. Essa seção destaca, ainda, a incorporação das relações alimentares às práticas ecológicas.

Nessa reflexão, a presente obra propõe que a soberania alimentar atua como contramovimento aos regimes alimentares, ao questionar o modelo de capitalização no qual a agroindustrialização está inserida. Esse questionamento está centrado na crítica ao processo de degradação socioecológica e na necessidade emergente do papel das práticas agroecológicas como restauradoras de uma agricultura mais sustentável diante de um panorama de vulnerabilidade ambiental. O autor destaca ainda que esse movimento não se resume apenas às questões ambientais ou reinvindicações campesinas, mas vem ganhando força e ressonância como movimento civilizatório em face às falhas do regime corporativo. Assim, diante de um contexto de crise do regime alimentar, tais questões surgem como alternativas para novas trajetórias e alternativas progressistas, com maior inclusão dos camponeses e agricultores familiares na produção de alimentos.

O quinto capítulo dessa obra aborda o debate dos regimes alimentares de uma forma mais ampla, no qual são apresentadas as interações e contradições desses regimes em diversas regiões do planeta. $\mathrm{O}$ autor constrói um paralelo das três fases dos regimes alimentares, com suas respectivas repercussões nas regiões do Leste Asiático, América Latina e Oriente Médio; ilustrando de maneira específica como os processos locais, nacionais e globais são regidos por essa dinâmica contraditória. Aliado a isso, embora o projeto do regime alimentar originalmente faça alusão ao esboço das relações entre o sistema estatal e às rotas internacionais de alimentos, o autor destaca que este regime tem gerado relações emergentes a respeito de questões de gênero, raça, mão-de-obra, temas ecológicos e nutricionais.

No capítulo seis, a obra discute sobre os períodos de ruptura e crise dos regimes alimentares, além de abordar de que forma ocorre a reestruturação da dinâmica de acumulação das estruturas regulatórias que regem as relações de produção de alimentos. A crise de acumulação do atual regime vem refletindo na erosão, a longo prazo, do aspecto estrutural do capitalismo neoliberal e de suas condições de produção. Com a ausência de uma ordem monetária internacional estável, o capital financeiro passa a privilegiar a circulação de ativos em detrimento da produção (especulações financeiras). Outra questão abordada pelo autor nessa seção é a dinâmica das instituições estatais e privadas de governança e sua interface com a apropriação de terras. Na medida em que o regime alimentar incorpora uma visão de modernização agrícola, intensificação da produção de alimentos e força a incorporação do pequeno agricultor nas cadeias de valor globais, a terra também passa a ser mais um elemento financiável que compõem esse sistema (financeirização da agricultura). Apesar das regras da OMC continuarem a institucionalizar um 'regime alimentar barato', por meio da validação do dumping praticado pelas nações hegemônicas, o autor enfatiza que novas tendências 
institucionais têm surgido e reestruturado o arcabouço do regime alimentar corporativo diante do panorama de erosão do modelo de acumulação de capital.

Por fim, o último capítulo aborda as relações de valor dos regimes alimentares e a importância da agricultura na produção de alimentos, no qual as forças estatais e industriais dependem da organização e divisão do trabalho. A partir das crises dos regimes alimentares do século passado, que evidenciaram as suas relações de poder com o mercado neoliberal, o autor destaca o movimento de soberania alimentar como reprodutor das relações de valor dentro dos regimes alimentares. Estes abordam temas e princípios morais relevantes na produção de alimentos, e que foram negligenciados na construção do modelo de produção industrial (reprodução social no campo, sustentabilidade ambiental, segurança alimentar, redução das desigualdades). Assim, Philip McMichael reafirma o entendimento de que a soberania alimentar é promotora do fenômeno de politização e conscientização nas relações de valor no regime alimentar, ressaltando a urgência de ampliação de formas alternativas e inclusivas de agricultura, pautadas na experiência de valor de troca entre os atores que os compõe.

Como considerações finais, destaco aos interessados em compreender e interpretar as questões que envolvem a questão agrária e o regime atual de produção de alimentos, que o presente livro atende à proposta de contribuir para o entendimento da dinâmica no mundo agrário, que fora profundamente transformado pelo processo contemporâneo de globalização e industrialização da economia neoliberal. Philip McMichael apresenta uma análise categórica e precisa das dimensões geopolítica e econômica do sistema agroalimentar atual, permitindo-nos compreender como se consolidou o regime alimentar contemporâneo e como este se coloca a serviço do sistema financeiro e transnacional do mercado mundial de commodities.

Desse modo, a obra problematiza como a questão da alimentação se distancia do dos consumidores e agricultores, sendo estruturado para contemplar os projetos de acumulação de capital; e como esse fenômeno tem implicação sobre as formas e padrões de consumo de alimentos. Nesse sentido, o autor apresenta, como proposta de transformação desse panorama, a soberania alimentar de base agroecológica como forma viável para criação de dinâmicas alternativas de produção e comercialização de alimentos, além de fornecer opções sociais e ambientais mais sustentáveis de alimentação e economia mais justa. Essa reflexão é relevante, uma vez que a alimentação influencia diretamente no contexto social e cultural das sociedades modernas, e que, com o aumento populacional, o desafio torna-se alimentar a população por meio de meios de produção mais equitativos e que conciliem questões ambientais e sociais nas sociedades rurais e urbanas.

\section{REFERÊNCIAS}

McMICHAEL, P. Regimes alimentares e questões agrárias. Tradução Sonia Midori. São Paulo; Porto Alegre: Unesp; UFRGS, 2016. 